\title{
Iron Corrosion in Occluded Water in Drinking Water Distribution Systems
}

\author{
Huiyan Tong, ${ }^{1, *}$ Xingshuai $\mathrm{Hu}^{1}$, Peng Zhao ${ }^{2, *}$, Hongwei Zhang ${ }^{2}$, Yimei Tian ${ }^{2}$ \\ ${ }^{1}$ Dalian University of Technology, Panjin, China \\ ${ }^{2}$ Department of Environmental Engineering, School of Environmental Science and Engineering, \\ Tianjin University, Tianjin, China \\ "E-mail: tonghuiyan@dlut.edu.cn
}

doi: $10.20964 / 2019.11 .18$

Received: 5 July 2019 / Accepted: 14 August 2019 / Published: 7 October 2019

Corrosion in drinking water distribution systems is a serious problem and has attracted increasing attention. This work characterizes the iron corrosion in occluded water and provides a perspective of many pipeline leakage incidents, especially the hidden leakage in pipes. Corrosion products were analysed, and the corrosion rate and behaviour of cast iron were compared by potentiodynamic polarization and electrochemical impedance spectroscopy measurements in occluded water and flowing water separately. In addition, a conceptual model of iron corrosion demonstrated complex interactions. This work extends the knowledge of the corrosion mechanism for local corrosion and the propagation of water leakage.

Keywords: drinking water distribution systems; water leakage; iron corrosion; occluded water; electrochemistry

\section{FULL TEXT}

(C) 2019 The Authors. Published by ESG (www.electrochemsci.org). This article is an open access article distributed under the terms and conditions of the Creative Commons Attribution license (http://creativecommons.org/licenses/by/4.0/). 